\title{
Numerical Analysis of a Convective Drying Chamber from Drying Air Velocity and Temperature Perspective
}

\author{
Miguel Andrés Daza Gómez ${ }^{1}$, Carlos Andrés Gómez Velasco \\ Nicolás Ratkovich ${ }^{\mathbf{1}}$, Juan Carlos Gómez Daza ${ }^{2}$ \\ ${ }^{1}$ Department of Chemical Engineering, Universidad de los Andes \\ Carrera 1 \# 18a-12, Bogota, Colombia \\ ma.daza299@uniandes.edu.co;n.rios262@uniandes.edu.co \\ ${ }^{2}$ Food Engineering School, BioNovo, Universidad del Valle \\ Calle 13 \# 100-00, Cali, Colombia \\ carlos.gomez.velasco@correounivalle.edu.co; juan.gomez.d@correounivalle.edu.co
}

\begin{abstract}
The drying industry has been growing considerably due to the great demand to have non-perishable food. Convective drying is one of the most popular equipment on drying industry (food, chemical, pharmaceutical, etc.). One of the drawbacks of this equipment when it is used for convective drying, is the non-uniformity in the final product quality. This study presents the development of a mathematical model trough Computational Fluids Dynamics (CFD). The drying chamber of a heat pump dryer is assessed from a drying air velocity and temperature profiles perspective. The model was developed solving different transport phenomena related equations. The established procedure was set up with the aim of evaluating the distribution of drying air velocity and temperature on the drying chamber to define the need of redesigning it. The profile results of the air velocity and the temperature show that, in fact there is a need to redesign the chamber. Only trays 2, 3, and 4 are the ones that could achieve the drying of the products. The proposed solution is to implement air distributors or to modify the tray positioning to make the distribution of the drying air and temperature homegeneous.
\end{abstract}

Keywords: Drying Industry, Convective Drying, CFD, Drying Air Distribution, Temperature Profile.

\section{Introduction}

The large demands of the drying industry, push constantly the development of new technologies and equipment. In the last decades, considerable efforts have been devoted to understanding the changes that occur in the drying operations, aiming to develop different ways to prevent undesirable quality losses [1]. Drying not only has applications in the food area, on the contrary, it expands to industries such as (bio)chemical pharmaceutical and agricultural sectors [2]. Among the equipment available in the drying industry, the heat pump dryer is the most used, which has a potential for heat recovery and a relatively high energy efficiency [3]. In heat pump dryers, sensible and latent heat of evaporated water is recovered and recycled by reheating the dehumidified air [4]. Currently, the use of drying processes has facilitated the use of new products, due to the easy incorporation of dry products into prepared dishes, snacks, bakery and pastry products, among others [5].

A good prediction of convective drying processes can be an important tool for the improvement of processes and minimization of problems such as high energy consumption, excessive load and wear on equipment and low yields [5], taking this into account, and considering that it depends on many factors, such as the speed of air, temperature and humidity of the air, level of turbulence, uniform air flow, etc. Keeping these factors, under the right conditions is the most challenging task at pilot and industrial scale [6]. Temperature and air velocity are the two factors that must be taken into account since they are difficult to measure due to a large number of sensors that must be placed in the chamber. The result of the drying process depends of the location of the material in the dryer, since the drying rate depends on the air flow in the drying chamber [7]. The use of a computer simulation of the mathematical model of the operation will allow to control the dynamics of the drying process, allowing the optimization of dryer performance from the perspective of energy consumption, efficiency and product quality, saving with the simulation both time and money [8]. 
The mathematical models in the drying process have been studied under different conditions and configurations (i.e. porous media and shrinkage) in diverse investigations being the majority of these an approximation in two dimensions. This has provided a great compression of the drying phenomenon, but the air flow in a convective dryer is usually turbulent and in three dimensions. Therefore, it is of great interest to perform an analysis of the process of turbulent flow and air distribution in a fully three-dimensional way, which implies a load not negligible on both computational and in the features and scope of the model [5]. A complete model of the drying process must take into consideration the interaction between heat-and-mass transfer within the material to be dried and the transfer to the drying air flow [9], several studies have been carried out in these aspects and their combinations, both at the simulation of models and at experimental levels performed by Cârlescu et al. [10], Villegas et al. [11], Lemus-Mondaca et al. [5] ([12]), Han et al. [13], Gómez \& Ochoa [14], Ozgen [15], Mohan [6], Lamnatou [9] among many others.

The aim of this study was to use a three-dimensional Computational Fluid Dynamics (CFD) model of a convective drying chamber of a heat pump dryer for the analysis of the behavior of the air flow in the chamber geometry and its effect on the temperature distribution during the convective drying process.

\section{Methodology}

\subsection{CFD Modelling}

CFD is an increasing tool to study and evaluate heat transfer in different systems and processes. CFD has the ability of changing the operation conditions in a useful and uncomplicated way than in an experimental facility. It is capable of changing flow rates that lead to different conditions in the processes or systems. The model can result in changes in the geometry to improve the system or process, in this case the heat and mass transfer in the convective dry chamber of a heat pump dryer. The CFD simulations are developed in the commercial software called STAR-CCM+ v12.02 (Siemens, Germany).

The geometrical domain is crucial thanks to the importance of being the computational domain in which the simulation is going to be developed. The experimental facility to be represented is shown in Fig. 1. The geometry is designed using Autodesk Inventor® v2017 and transformed into a CAD model.

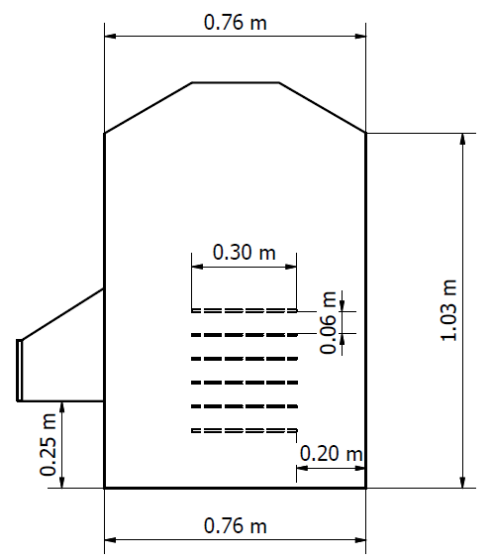

(a)

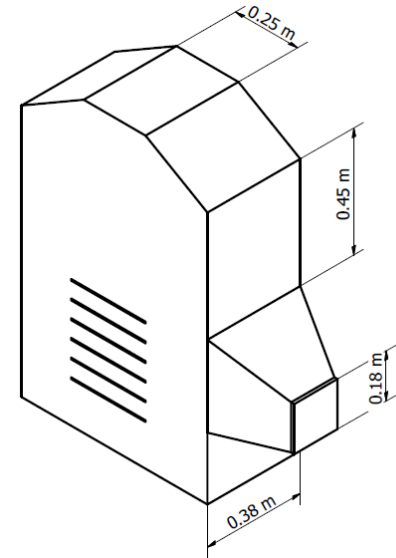

(b)

Fig. 1: Dimensions of the convective drying chamber (a) Lateral view and (b) Diagonal view.

Grid generation is an important step for the validation of the research project. There are several mesh arrangements depending on the modelled system, in this case it is used polyhedral-type mesh. This type gives each cell a large number of immediate neighbouring cells of which the software can obtain information and linear shapes functions, resulting in a better approximation of the gradients, lower skewness angles and a more accurate flux calculation when compared to a tetrahedral mesh [16]. Another benefit of using a polyhedral-type mesh over other types for this particular application is that polyhedral cells allow to easily and gradually control grid size changes (for coarsening or refining certain regions of the system) to avoid the sudden size changes that can result when using some trimmed hexahedral cell [16]. 
The specification of the boundary and initial conditions of the system is a significant step in the pre-processing stage in CFD. The inlet and outlet of the spatial discretization are modelled as velocity inlet and flow split outlet, respectively. The remaining of the discretization is modelled as a wall condition.

An important step is the physical model selection. In this case it is modelled as a transient system with a flow regimen turbulence that is exemplified with the $k$ - $\varepsilon$ model. This model allows to decompose the instantaneous variables in the Navier-Stokes (NS) equations into their mean and their fluctuations [17]. The additional models that are used are: gas, segregated flow, and gravity. It is important to mention that the air temperature and velocity modelled as $313.15 \mathrm{~K}$ and 1 $\mathrm{m} / \mathrm{s}$, respectively.

To validate the CFD model the simulations must be transient as specified before. The necessary parameters specified in the model are time step, inner iterations per time step and maximum physical time. The most important parameter is the time step, because, if it is not correctly calculated, diverse problems can appear. One of these problems is convergence, which presents when the time step is larger than the velocity magnitude. This causes that intermediate points are not solved, producing that the next points have no previous solution and the CFD solver assuming those solutions that lead to divergence. The CFL (Courant - Friedrichs - Lewy) condition is used to avoid the divergence problem. The recommended CFL values are below 0.1 to capture accurately the interface.

The main results that are obtained from the simulations are: temperature and velocity profiles.

\section{Results and Discussion}

The results of the velocity profile can be seen in Fig. 2. It can be observed that distribution of the air does not present in a uniform manner. The velocity is optimum for the heat transfer by convection only in trays 2,3 , and 4 from top to bottom, also a stagnation occurring in the bottom and top of the chamber is observed. This leads to reconsider the tray positioning and the implementation of air distributors such as dampers and diffusers. In addition, it can be observed that the chamber has two recirculation areas, one at the bottom (below tray 4) and one at the top, near the exit of the air. This can be an advantage if the distribution of the air is improved as it is mentioned above.
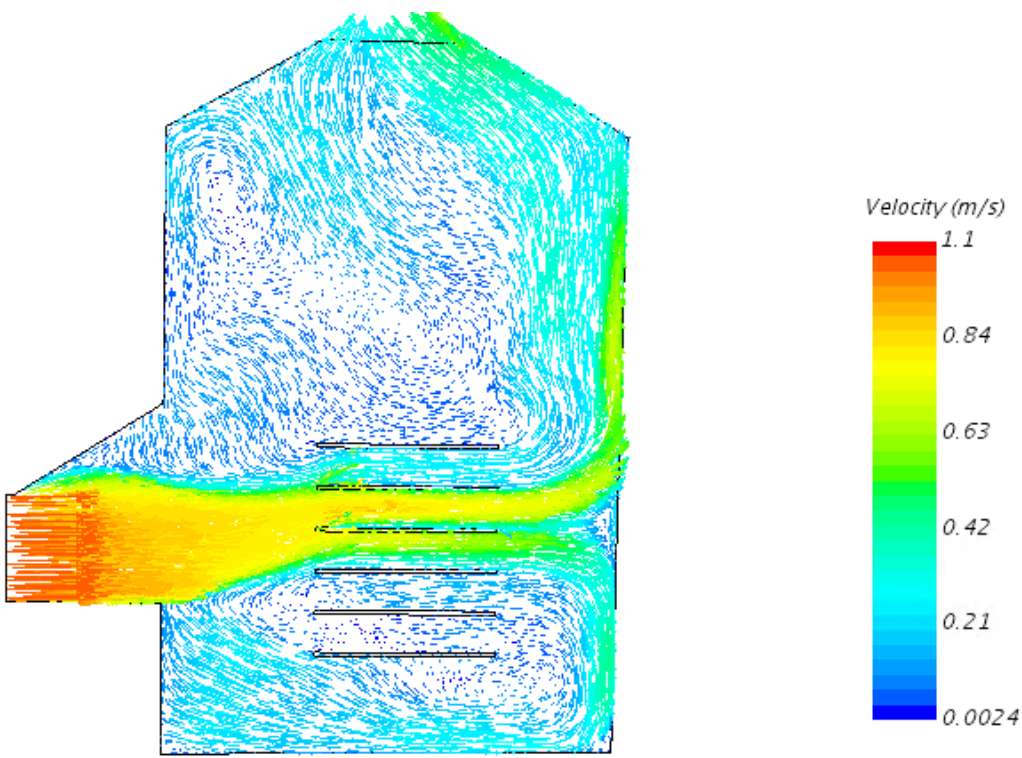

\section{Solution Time $11.326(s)$}

Fig. 2: Velocity profile in the drying chamber.

Temperature distribution is observed in Fig. 3 at different times of the solution. It shows that the temperature profile is not as uniform as expected. As well as in the velocity profile, only trays 2,3 , and 4 (from top to bottom) are receiving the required amount of temperature that is needed to make the convective drying chamber successful. Another observation is the fact that the temperature starts to stabilize. In the very first seconds the chamber will have the highest temperature in all of its domain, while in a later time the effective area decreases in a small proportion and the temperature starts to be 
uniform in the top of the chamber and at the bottom where is not useful, especially on trays 5 and 6 where drying will be less efficient, leading to an uneven or poor product quality.

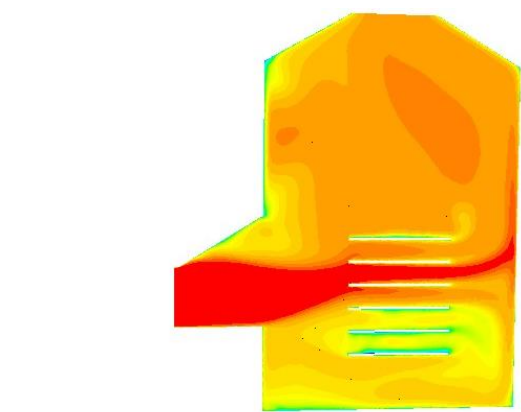

Solution Time $10.087(s)$

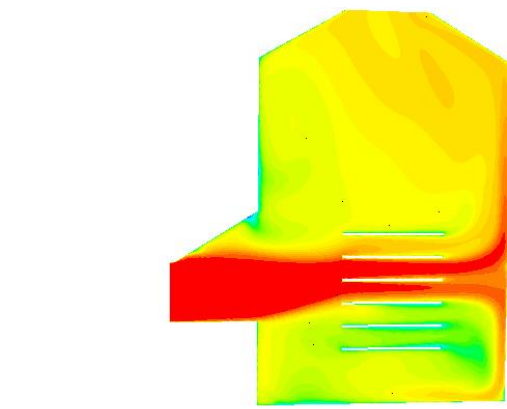

Solution Time $26.46(s)$

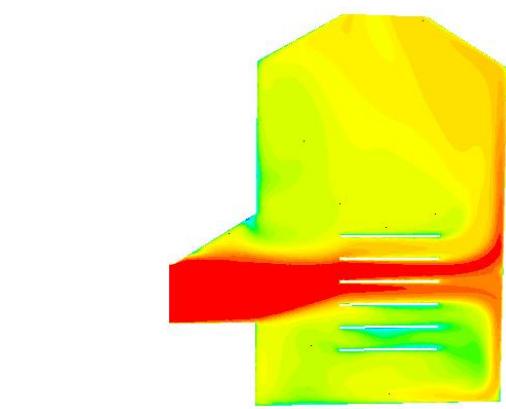

Solution Time 44.59 (s)

(b)

(c)

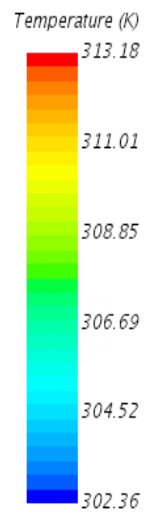

Fig. 3: Temperature distribution at different times. (a) $10.087 \mathrm{~s}$; (b) $26.46 \mathrm{~s}$; (c) $44.59 \mathrm{~s}$.

Air temperature and velocity are plotted in Fig. 4. According to this, there is a relationship between these two factors that supports the behavior observed on Fig. 2 and Fig. 3, if stagnation of air increase (decrease velocity) temperature drops resulting in a poor drying as is observed in top and lower regions on Fig. 2 and Fig. 3. This implies uneven quality products or even worst, increase production time to reprocess or keep drying the product.

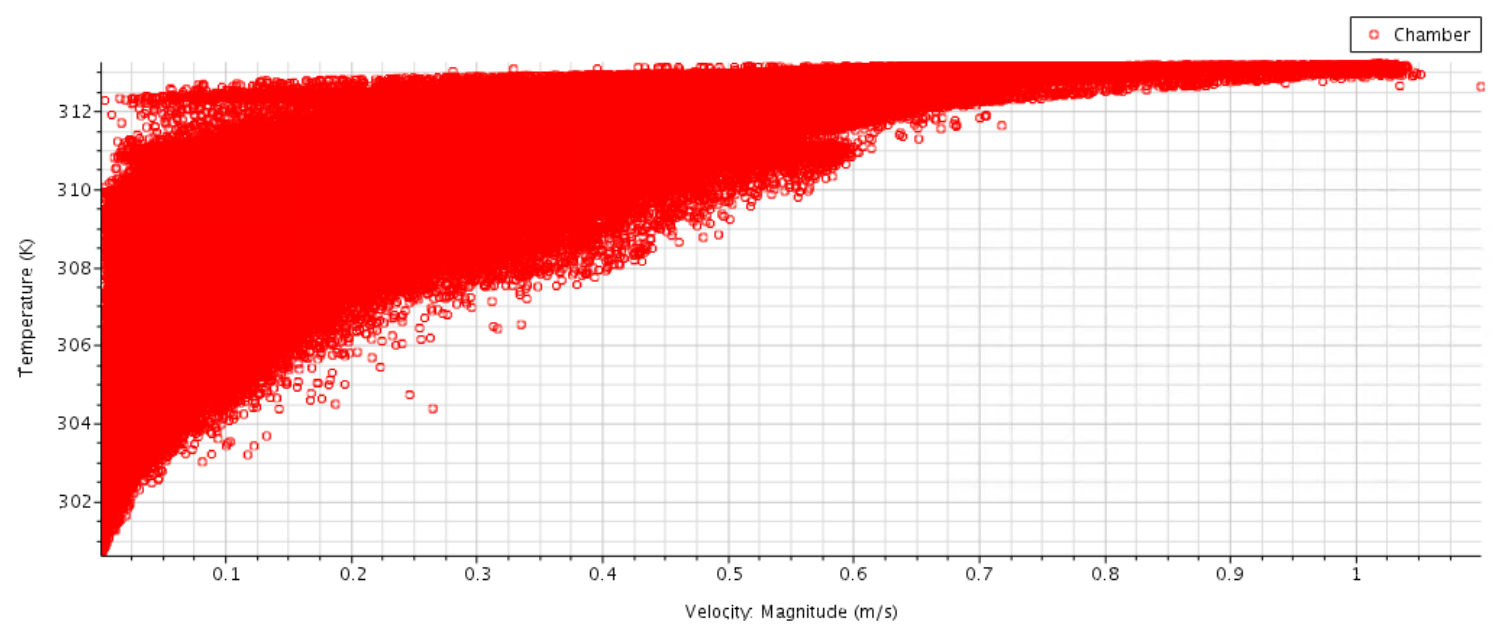

Fig. 4: Velocity vs. temperature in the drying chamber.

Air distribution is a characteristic that must be assessed in order to improve drying and achieve a uniform distribution. This has been done by researchers, such as Mathioulakis et al. [18], who assessed the relationship between air velocity and weight loss on drying and agree with observations made in this study. As well as the work made by Amanlou \& Zomorodia they proposed different designs to improve drying process. One of the observations made in their work is that low air velocity and poor air distribution implies a poor design and ergo a bad or longer operation which is seen in the results of this study.

\section{Conclusion}

To understand the convective drying process, a CFD simulation was implemented using a transient system model with the $k-\varepsilon$ model for turbulence and the CFL criterion. This is a very useful and powerful tool to achieve the desired 
assessment allowing to identify the temperature and air profiles in the convective drying chamber. The results of the air distribution show that there are two specific areas of low air velocity that tends to create recirculation. They are located at the air exit and the other one at the bottom of the chamber that results in a poor drying. Besides this, the temperature profile shows only a homogeneous drying in half of the trays, reducing drying efficiency drastically, especially for the bottom ones. The need of air distributers or dampers are necessary to deliver and improve the convective chamber. Simulation by the means of CFD demonstrated to be a trustworthy optimization tool in order to avoid unnecessary and expensive experiments to improve the design, and can be used in a subsequent research to predict the drying time if it is implemented a thin film model.

\section{Acknowledgements}

We would like to thank the conjoint effort between Universidad de los Andes and Universidad del Valle for the opportunity to work in this project. It is a great chance to exchange knowledge and develop a model that can help in the development of an efficient equipment for the drying industry.

\section{References}

[1] A. S. Mujumdar, "Research and development in drying: Recent trends and future prospects," Dry. Technol., vol. 22, no. 1-2, pp. 1-26, 2004.

[2] T. J. Jamaleddine and M. B. Ray, "Application of Computational Fluid Dynamics for Simulation of Drying Processes: A Review," Dry. Technol., vol. 28, no. 2, pp. 120-154, 2010.

[3] Y. Tong, T. Kozai, N. Nishioka, and K. Ohyama, "Greenhouse heating using heat pumps with a high coefficient of performance (COP)," Biosyst. Eng., vol. 106, no. 4, pp. 405-411, 2010.

[4] Z. Erbay and A. Hepbasli, "Advanced exergoeconomic evaluation of a heat pump food dryer," Biosyst. Eng., vol. 124, pp. 29-39, 2014.

[5] R. A. Lemus-Mondaca, A. Vega-Gálvez, C. E. Zambra, and N. O. Moraga, "Modeling 3D conjugate heat and mass transfer for turbulent air drying of Chilean papaya in a direct contact dryer," Heat Mass Transf., vol. 53, no. 1, pp. 11-24, 2017.

[6] V. P. C. Mohan and P. Talukdar, "Design of an experimental set up for convective drying: experimental studies at different drying temperature," Heat Mass Transf., vol. 49, no. 1, pp. 31-40, 2013.

[7] B. Xia and D. W. Sun, "Applications of computational fluid dynamics (CFD) in the food industry: A review," Comput. Electron. Agric., vol. 34, no. 1-3, pp. 5-24, 2002.

[8] D. Zare, S. Minaei, M. Mohamad Zadeh, and M. H. Khoshtaghaza, "Computer simulation of rough rice drying in a batch dryer," Energy Convers. Manag., vol. 47, no. 18-19, pp. 3241-3254, 2006.

[9] C. Lamnatou, E. Papanicolaou, V. Belessiotis, and N. Kyriakis, "Conjugate Heat and Mass Transfer from a Drying Rectangular Cylinder in Confined Air Flow," Numer. Heat Transf. Part A Appl., vol. 56, no. 5, pp. 379-405, 2009.

[10] P.-M. Cârlescu, V. Arsenoaia, R. Roşca, and I. Țenu, "CFD simulation of heat and mass transfer during apricots drying," LWT - Food Sci. Technol., vol. 85, pp. 479-486, 2017.

[11] J. F. Villegas, H. S. De La Cruz, F. B. Altamar, and W. O. Lozano, "CFD numeric simulation to obtain the proper parameters of corozo drying (Bactris guineensis)," Contemp. Eng. Sci., vol. 10, no. 15, pp. 703-711, 2017.

[12] A. Pantokratoras, "Comment on the paper 'Modeling 3D conjugate heat and mass transfer for turbulent air drying of Chilean papaya in a direct contact dryer, Roberto A. Lemus-Mondaca, Antonio Vega Galvez, Carlos E. Zambra, Nelson O. Moraga, Heat Mass Transfer, 2017, 53:11-24," Heat Mass Transf., vol. 54, no. 2, pp. 591-592, 2018.

[13] J. Han, R. BadÍa-melis, X. Yang, L. Ruiz-garcia, J. Qian, and C. Zhao, "CFD Simulation of Airflow and Heat Transfer During Forced-Air Precooling of Apples,” J. Food Process Eng., vol. 40, no. 2, p. e12390, 2017.

[14] J. C. Gómez Daza and C. I. Ochoa Martínez, "Kinetic aspects of a dried thin layer carrot in a heat pump dryer," Dyna, vol. 83, no. 195, pp. 16-20, 2016.

[15] F. Ozgen, "Experimental investigation of drying characteristics of cornelian cherry fruits (Cornus mas L.)," Heat Mass Transf., vol. 51, no. 3, pp. 343-352, 2015.

[16] Siemens, "STAR-CCM+ Documentation." NY, 2015.

[17] P. D. Viviescas Pico and J. P. Valdés Ujueta, "Experimental and CFD modelling of the drift flux in two-phase air(non)Newtonian slug-flow pattern flow along horizontal and inclined pipelines," Universidad de los Andes, 2017. 
[18] E. Mathioulakis, V. T. Karathanos, and V. G. Belessiotis, "Simulation of air movement in a dryer by computational fluid dynamics: Application for the drying of fruits," J. Food Eng., vol. 36, no. 2, pp. 183-200, 1998.

[19] Y. Amanlou and A. Zomorodian, "Applying CFD for designing a new fruit cabinet dryer," J. Food Eng., vol. 101, no. 1, pp. 8-15, 2010. 